\title{
La crisis del abuso sexual de menores en la iglesia católica: modelos de gestión
}

\author{
Dr. Saúl Manuel Albor Guzmán \\ sm.albor@ugto.mx \\ Universidad de Guanajuato, México
}

\section{RESUMEN}

El artículo tiene por objetivo identificar los diversos modelos de gestión que se han formulado en el interior de la Iglesia Católica para afrontar la crisis del abuso sexual de menores. Se han analizado dos posturas al respecto, una que representaría la línea oficial de la Institución eclesiástica, caracterizada por una visión más teológica y espiritual ante el problema y encauzada hacia una reforma eclesial, y una segunda, la proveniente de catolicismos particularistas o de la periferia que propugnan un cambio estructural, de poder, del sistema eclesiástico. Por ello, nos avocaremos al estudio de estas hermenéuticas que se encuentran en la base de esas propuestas de reforma eclesial, atendiendo a sus características más importantes, sus exponentes, el pensamiento que las inspira y las tensiones surgidas para explicar y entender el significado de la crisis.

Palabras clave: abuso sexual de menores; clericalismo; Iglesia católica; poder religioso; reforma eclesial. 


\title{
The crisis of sexual abuse of minors in the catholic church: management models
}

\begin{abstract}
The article aims to identify the various management models that have been formulated within the Catholic Church to face the crisis of sexual abuse of minors. Two positions have been analyzed in this regard, one that would represent the official line of the ecclesiastical institution, characterized by a more theological and spiritual vision of the problem and directed towards an ecclesial reform, and a second, that coming from particularist Catholics or from the periphery that advocate a structural change, of power, of the ecclesiastical system. Therefore, we will focus on the study of these hermeneutics that are found in the background in these proposals for ecclesial reform, taking into account their most important characteristics, their exponents, the thought that inspires them and the tensions that have arisen to explain and understand the meaning of the crisis.
\end{abstract}

Keywords: sexual abuse of minors; clericalism; Catholic Church; religious power; ecclesial reform.

Artículo recibido: 20. Julio. 2021 Aceptado para publicación: 18. Agosto. 2021

Correspondencia: sm.albor@ugto.mx Conflictos de Interés: Ninguna que declarar

\section{INTRODUCCIÓN}


Hay parteaguas epocales como fue la revolución cultural en 1968. Tan lejos y tan cerca. La humanidad en crisis, aunque la humanidad siempre ha estado y estará en crisis, como el mismo cristianismo que se encuentra en medio de la humanidad. Al concluirse el Concilio Vaticano II (1962-1965) se saludaba el surgimiento de una primavera en la Iglesia, para el cristianismo, pero advino el invierno, se asiste a una crisis de identidad del mismo cristianismo a partir de 1968 (el posconcilio que llega a nuestros días) y ello para señalar una época pero esa crisis de identidad hundía sus raíces más atrás.

La situación del abuso de menores como fenómeno internacional que en los últimos años han ido apareciendo en diversos contextos del catolicismo periférico: Estados Unidos, Australia, Irlanda, Alemania, Países Bajos, Chile, México, como el caso del fundador de los Legionarios de Cristo, por citar los más mediáticos, ha provocado una crisis a la que se pretende dar explicación, entender el significado y la respuesta que se ha dado al porqué de ese problema y su forma de gestionarlo.

El abuso de menores ha implicado una crisis larvada desde hace décadas y cuyas respuestas a esta problemática varía, por una parte se encuentra aquélla que considera a la Iglesia como una estructura organizativa a la que hay que cambiar, toda vez que ha ocasionado el abuso de menores por las disfunciones sistémicas del poder eclesiástico y, por la otra, la respuesta institucional romana que considera que las causas de ese problema responden a una decadencia moral y religiosa y hace frente a los nuevos empoderamientos intra eclesiales cuyos principios aparecen, por ser los más mediáticos, en Alemania, Estados Unidos, y en el contexto de discusión en torno al sínodo de la Amazonia, por citar algunos más representativos.

Ante el problema del abuso de menores en la Iglesia han surgido pues esas hermenéuticas y propuestas de reforma en las que subyacen diversos enfoques y concepciones teológicas y filosóficas que sustentan los diversos modelos de gestión emprendidos para afrontar la crisis.

\section{Tensiones entre particularismos eclesiales en la Iglesia Universal: el caso alemán.}

Un claro ejemplo de ello son las tensiones que se detectan en la Iglesia Alemana que en diversos sectores se han considerado como de vanguardia por sus posiciones frente a Roma y que han emprendido lo que denominan el camino sinodal y por otro lado los sectores más proclives al Vaticano, mismas que nos permitirán contextualizar los intentos 
de reforma emprendidos por algunos sectores de la Iglesia alemana derivado de la crisis abuso sexual de menores.

Mencionamos el caso alemán por ser el más protagónico y mediático y que ha influido hasta en el sínodo ${ }^{1}$ de la Amazonia. La Iglesia en Alemania en 2019 ha emprendido lo que se ha denominado el camino sinodal, que no es más que el ir juntos entre la Jerarquía y los laicos con el objetivo de atender los principales retos que han surgido como el caso del abuso de menores.

Desde hace décadas existe un movimiento muy influyente del catolicismo reformista como es el caso del Comité Central de Católicos Alemanes, Zentralkomitee der deutschen Katholiken (Zdk en adelante), el cual lidera a las organizaciones laicas católicas de Alemania y que ha venido proponiendo, paradójicamente, nuevos clericalismos, como si los laicos quisieran clericalizarse, lo que llama la atención en los nuevos empoderamientos propuestos.

Parecería que estas controversias fueran sólo cuestiones ad intra del catolicismo y, en efecto, lo son, pero se menciona por la razón de que algunos sectores de la Iglesia han sido influidos por ideologías de diversos signos y el poder de los medios de comunicación tienen la posibilidad de crear tendencias dentro de la Iglesia. Los laicos alemanes, muy bien organizados hay que decirlo en contraste con otros países, paradójicamente, están exigiendo y buscando nuevos empoderamientos: sacerdotes casados, diaconisas o mujeres ordenadas dentro del contexto de lo que se ha llamado la responsabilidad sinodal. Los Obispos alemanes se reunieron con los representantes del Zdk para discutir los Informes de los cuatro foros preparatorios sobre poder, sacerdocio, moral sexual y mujeres en los que se sintetizan el nuevo modo de pensar de crecientes sectores de la Iglesia germana.

En uno de los Informes $(2019)^{2}$ se aborda precisamente la discusión sobre el Poder y separación de poderes en la Iglesia, reconociéndose que el paradigma romano tiene un sistema monárquico que tiene que abrirse al modelo democrático y de respeto a los derechos humanos. 
Es decir, el contenido del Informe (en lo subsecuente) es un alegato por la reforma eclesial desde el empoderamiento de laicos en las estructuras de poder en la Institución eclesiástica utilizando, para ello, un pensamiento teológico para llegar a pensar la iglesia de manera diferente: Wir nutzen die Möglichkeiten der Theologie, Kirche anders zu denken (p. 4).

Se ha resaltado la misión y naturaleza del cristiano como un empoderarse al incrustarse en las estructuras burocráticas de la Iglesia: Die Berufung und Bevollmächtigung des Volkes Gottes ist in der Taufe theologisch begründet. Sie besitzt im sensus fidelium eine theologisch grundlegende Qualität. Die Taufe begründet (p. 9).

Es decir, el Informe entiende la reforma eclesial desde el empoderamiento y no por la santidad y/o renovación espiritual de los fieles cristianos en su búsqueda e identificación con Jesucristo, es decir, el ser cristiano se agota en ser sólo buscadores de empoderamiento en las estructuras eclesiales.

Ante nuevas realidades sociales como laicos que puedan pronunciar homilías o mujeres que puedan sean ordenadas ministros, el Informe pretende activar en la práctica esos empoderamientos, aunque ello tampoco garantiza que esos empoderamientos puedan incurrir en el abuso de poder, simplemente por su situación en razón del 'pecado' que es igual para todos los cristianos: Raum geben, ohne mit ihm identifiziert werden zu können. Jegliche Sakralisierung und Fixierung bestimmter, historisch gewachsener sozialer Realitäten ist deshalb aus theologischen; (p. 9) lo que se pretende pues es la sacralización y fijación de estos nuevos espacios a los que se pretende combatir, nos encontramos ante un nuevo proceso de clericalización de la realidad eclesial.

Efectivamente, los que siguen a Jesús tienen el derecho y la responsabilidad de predicar el Evangelio pero conforme a la vocación y naturaleza de los diversos carismas y oficios de cada quién, el Informe (pp. 10-11) pretende una nueva uniformización del apostolado y la evangelización desde estructuras administrativas, lo que contrasta con la reforma y propuestas del centro romano que considera que el experimentar el poder de liberación del Evangelio no se reduce en incrustarse sólo en estructuras administrativas.

Con una visión administrativista de la Iglesia, el Informe sostiene que: Das neutestamentliche Zeugnis von Macht, Missbrauch und Ohnmacht verlangt nach einer Konkretisierung, die Macht und Gewaltenteilung in der Kirche neu organisiert, um die Verkündigung des Evangeliums zu fördern (p. 12). 
Esta pretensión de que se reorganice el poder y la separación de poderes en la iglesia para promover la proclamación del evangelio, implica la nueva clericalización de los nuevos empoderados que al llegar al poder, desde arriba, acabarían con la crisis sistémica. Pero nada garantiza que los nuevos empoderamientos puedan incurrir, asimismo, en disfunciones sistémicas.

En el Camino sinodal alemán se discute que los sacerdotes sean casados y se discuta abiertamente el acceso de las mujeres a los ministerios eclesiales, incluido el ministerio ordenado: Auf dem Synodalen Weg ist über verheiratete Priester und über Zugänge von Frauen zu diesen Ämtern, einschließlich des Weiheamtes, offen zu diskutieren. Mögliche Veränderungen brauchen ein vertrauensvolles und offenes Gespräch, um geklärt werden zu können, sie müssen in Einheit mit der ganzen Kirche beschlossen und umgesetzt werden (p. 13), sin embargo, se reconoce que éstos temas deben ser implementados en unidad con toda la Iglesia universal, ya que el particularismo eclesial no puede primar sobre el sentir de la Iglesia bajo la unidad de Roma.

Según el enfoque católico, más espiritual del centro Vaticano, la autoridad de los Pastores es un don específico del Espíritu de Cristo, no una función delegada y representativa del pueblo, porque se hace necesario distinguir entre el proceso para elaborar una decisión en la que se consulta a los bautizados que dialogan, argumentan, proponen, por una parte y, por la otra, la decisión pastoral que compete a la autoridad del Obispo, garante de la apostolicidad y catolicidad.

Por su parte, el Cardenal Arzobispo de Munich Reinhardt Marx (2019) que ha asumido un rol protagónico en este camino sinodal alemán y es parte del Consejo de Asesores del Papa Francisco, en el Encuentro eclesial celebrado en 2019 para tratar sobre la protección de los menores en la Iglesia, ha considerado que la meta de la Iglesia es que requiere de una administración buena y totalmente funcional.

Los alemanes son conocidos por su tendencia hacia la administración, no obstante reconoce Reinhardt Marx (2019) que The Spirit of God cannot possibly be captured in a file or folder. God's love is reflected in specific acts of caring for the people, rather than in administrative documents. Prayer is much stronger than any number of administrative procedures.

Asimismo, argumenta que The sexual abuse of children and youths is in no small measure due to the abuse of power in the area of administration, y no propiamente a una crisis 
sistémica del poder eclesial, más bien, la causa del abuso se deben a otros factores y sí, en el conocimiento posterior de estos crímenes se denotan las disfuncionalidades administrativas, como también en la transparencia e implementación de los procedimientos administrativos para enjuiciar y atacar el problema de la pederastia. Pero aquí entran en juego muchos episcopados de catolicismos de la periferia. No es que la administración en sí haya sido origen del abuso sino de las personas en concreto, What is decisive is always the personal attitude of those who work in administration, and those responsible for it, concluye Marx.

\section{Iglesias particulares y Reforma eclesial: la propuesta de Benedicto XVI.}

En el contexto eclesial alemán, saltan a la luz opciones eclesiológicas (visión de empoderamiento) más que teológicas (espiritual o de reforma de la Iglesia que sostiene el Vaticano, pero con medidas tales como la expulsión del estado clerical a los infractores).

Al respecto, no cabe duda que Benedicto XVI ha sido protagonista fundamental en el debate de la reforma necesaria de la Iglesia con ocasión del abuso sexual de menores. El Papa teólogo representa claramente una postura ante los nuevos empoderamientos clericales los cuales reflejan cierto complejo antiromano por el papel que adquieren cada vez más los intentos de las iglesias locales, las llamadas periferias.

Desde antes de ser Papa, Ratzinger (1992) debatía con las diversas teologías y eclesiologías posconciliares a las que consideraba como fruto de la teología liberal de raigambre protestante cuya concepción sobre lo que es la Iglesia se refleja claramente en dos tendencias teológicas, la a) escatológica que considera a Jesús como antagonista del culto y a las instituciones antiguas, esquema en el que se

reduce el Antiguo Testamento a sacerdote y profeta, a culto, instituciones y derecho por una parte, y profecía, carisma y libertad creadora por otra...ruptura y paso de lo institucional a lo carismático, como fin de las religiones o, en todo caso, como fe no mundana que crea y renueva de continuo sus propias formas (p. 10).

Por esta razón no se podría hablar de la fundación de la Iglesia. En otra perspectiva, la b) interpretación bíblica con orientación marxista, como algunas teologías de la liberación, imprime en la eclesiología ${ }^{3}$ nuevos aspectos, es vista desde su dialéctica, se escinde la 
Biblia en sacerdotes y profetas, correspondiéndole la distinción institución y pueblo, que desarrollaría las intenciones de Jesús para combatir la institución en aras del reino centrismo, lo cual es para el propio Ratzinger (2005) una idea secular utópica del reino en la que Dios ha desaparecido.

Debe considerarse que el Concilio Vaticano II (1964) en su Constitución dogmática Lumen gentium (LG en lo subsecuente) habla claramente de la constitución jerárquica de la Iglesia, Ratzinger ha resumido los diversos objetivos de este acontecimiento eclesial: el primer objetivo era la reforma de la liturgia pretendiéndose que se hablara de Dios, la Iglesia debe hablar sobre Dios, adorarle, el Misterio pascual es el centro del ser cristiano, y por tanto de la vida cristiana, del año, del tiempo cristiano, expresado en el tiempo pascual y en el domingo, que siempre es el día de la Resurrección. El Vaticano II con este documento comienza precisamente con la profundización de la liturgia (celebración, culto).

El segundo objetivo es el de la eclesiología en el que nos detendremos por razón del presente estudio, el Vaticano II vendrá a completar e integrar la eclesiología del Vaticano $\mathrm{I}^{4}$, nos encontramos pues ante una eclesiología acabada e integrada por ambos concilios. Benedicto XVI (2013) interpretando al Vaticano II sostenía que desde el Vaticano I se redescubrió la idea de la Iglesia como Cuerpo Místico de Cristo entendiéndose al respecto que

la Iglesia no es una organización, algo estructural, jurídico, institucional — también es esto-, sino que es un organismo, una realidad vital, que entra en mi alma, de manera que yo mismo, precisamente con mi alma creyente, soy elemento constructivo de la Iglesia como tal...somos la Iglesia, la Iglesia no es una estructura; nosotros mismos, los cristianos, juntos, somos todos el Cuerpo vivo de la Iglesia. Y, naturalmente, esto es válido en el sentido de que nosotros, el verdadero 'nosotros' de los creyentes, junto al 'Yo' de Cristo, es la Iglesia; cada uno de nosotros, no 'un nosotros', un grupo que se declara Iglesia. No: este 'nosotros somos Iglesia' exige precisamente mi inserción en el gran 'nosotros' de los creyentes de todos los tiempos y lugares. 
Es decir, estamos ante una eclesiología más teológica, fue el Vaticano II el que introdujo el concepto de Iglesia como Pueblo de Dios y se fue dando cierta crítica al concepto de Cuerpo de Cristo, por ser más espiritual, demasiado exclusivo.

LG al profundizar en la categoría del Pueblo de Dios lo relaciona con la esencia y constitución jerárquica de la Iglesia, de ahí que la Iglesia sea entendida también como Sacramento, desde el posconcilio se ha pretendido una nueva concepción de la jerarquía y del laicado, que va más allá de la propia LG, pretendiendo como si todo bautizado fuese ya portador de la plena potestad sagrada, incluso, para celebrar la Misa y la jerarquía sólo fuera un factor de favorecer el buen orden, esto hay que tenerlo presente en la concepción que tienen los nuevos empoderamientos clericales.

Desde luego que todos los bautizados pertenecen al Pueblo de Dios, pero la misma LG, distingue claramente que la comunidad sacerdotal de los bautizados no es más que la proyección del sacerdocio de Jesucristo: el sacerdocio común de los fieles y el sacerdocio ministerial o jerárquico, este último, por la potestad sagrada que tiene, forma y dirige el pueblo sacerdotal, confecciona el sacrificio eucarístico en la persona de Cristo y lo ofrece en nombre de todo el pueblo a Dios (LG. 10).

Los intentos de reestructurar la iglesia conforme al camino sinodal alemán y en otros modelos eclesiales en los que se pretende clericalizar a los laicos van más allá de toda reforma, incluso, pueden representar una regresión. La discusión sobre el derecho al sacerdocio por parte de las mujeres, aunque ya lo sean por el bautismo, pero ordenado a su papel como el de cualquier otro laico varón, representa un intento de empoderamiento que, según el centro romano, es antievangélico.

El mismo Ratzinger (2005) resalta el carácter mariano de la Iglesia que le permite decir que la Iglesia nunca ha sido hecha sino engendrada cuando el alma de María se despertó el Fiat:

La Iglesia no es aparato, no es mera institución, ni es tampoco una de tantas entidades sociológicas. La Iglesia es persona. Ella es una mujer. Es madre. Es viviente. La comprensión mariana de la Iglesia representa el más decidido rechazo de un concepto de Iglesia meramente organizativo y burocrático. A la Iglesia no podemos nosotros hacerla. Debemos ser Iglesia. Y sólo en la medida en que la fe, más allá de nuestro hacer, forje nuestro ser, somos Iglesia (p. 25). 
Es decir, todos los bautizados deben y pueden participar celosamente en la obra salvífica de la Iglesia y no reducirlo a sólo empoderamientos clericales, la Lumen gentium destaca el papel del laico:

todas sus obras, sus oraciones e iniciativas apostólicas, la vida conyugal y familiar, el cotidiano trabajo, el descanso de alma y de cuerpo, si son hechos en el Espíritu, e incluso las mismas pruebas de la vida si se sobrellevan pacientemente, se convierten en sacrificios espirituales, aceptables a Dios por Jesucristo, que en la celebración de la Eucaristía se ofrecen piadosísimamente al Padre junto con la oblación del cuerpo del Señor...los laicos, como adoradores que en todo lugar actúan santamente, consagran el mundo mismo a Dios (34).

El Papa Francisco (2018) resalta el cometido de los cristianos en la actualidad, lo único que moviliza es el testimonio de la santidad que

nos recuerda que la Iglesia no necesita tantos burócratas y funcionarios, sino misioneros apasionados, devorados por el entusiasmo de comunicar la verdadera vida. Los santos sorprenden, desinstalan, porque sus vidas nos invitan a salir de la mediocridad tranquila y anestesiante (Punto 138).

Benedicto XVI (2015) ha distinguido claramente la labor evangélica del Vaticano II para una verdadera renovación de la Iglesia, el cual ha sido interpretado por poderes como los medios de comunicación que no se movían dentro del ámbito de la fe del Vaticano II, sino con una hermenéutica distinta:

Era una hermenéutica política. Para los medios de comunicación, el Concilio era una lucha política, una lucha de poder entre diversas corrientes en la Iglesia. Era obvio que los medios de comunicación tomaran partido por aquella parte que les parecía más conforme con su mundo. Estaban los que buscaban la descentralización de la Iglesia, el poder para los obispos y después, a través de la palabra 'Pueblo de Dios', el poder del pueblo, de los laicos. Estaba esta triple cuestión: el poder del Papa, transferido después al poder de los obispos y al poder de todos, soberanía popular. 
Para Ratzinger la crisis que ha venido afectando al cristianismo europeo, siendo el alemán uno de los claros de ejemplos, ha sido, en parte, por el clima cultural del posconcilio que más que una crisis eclesial es una crisis más profunda, es una crisis de Dios.

La Iglesia pasa por una crisis generada por el olvido del espíritu del Concilio Vaticano II que habló, sobre todo, de Dios en medio del mundo moderno, esta es la tesis de Ratzinger (2000):

el Vaticano II quiso claramente insertar y subordinar el discurso sobre la Iglesia al discurso sobre Dios; quiso proponer una eclesiología en sentido propiamente teo-lógico, pero la acogida del Concilio hasta ahora ha omitido esta característica determinante, privilegiando algunas afirmaciones eclesiológicas; se ha fijado en algunas palabras aisladas, llamativas, y así no ha captado todas las grandes perspectivas de los padres conciliares.

Por ello, una eclesiología que considere una Iglesia que exista sólo para sí misma es superflua, la crisis de la Iglesia es una crisis de Dios, si se prescinde de Dios, y esto es lógico si se está hablando de la Iglesia, todo lo demás se reducirá a una lucha por el poder. Ratzinger (1992) señalará la esencia de la verdadera reforma eclesial, frente al activismo, se propone el dejar que la propia luz de Dios nos salga al encuentro, que nos admiremos ante el Misterio que nos precede, que miremos lo más Grande, la reforma va más allá de un mero activismo eclesial como si fuera más cristiano el que participa en comités eclesiásticos y no el que vive de la palabra, del sacramento y del amor que proviene de la fe, de los sencillos:

La liberación fundamental que la Iglesia puede darnos es permanecer en el horizonte de lo eterno, es salir fuera de los límites de nuestro saber y de nuestro poder. Por eso es la fe en toda su grandeza inconmensurable la reforma eclesial que necesitamos constantemente; a partir de ella debemos poner siempre a prueba aquéllas instituciones que nosotros mismos hemos construido en la Iglesia (p. 86).

Ante un clericalismo soterrado en sectores laicos, habrá que reconsiderar que el sacramento del Orden no es un reparto de poderes sino es una expropiación de sí mismo al servicio de los demás. Donde mayor es la responsabilidad mayor la auto expropiación. 
Precisamente en una reunión con el Consejo del Zdk Benedicto XVI (2011) advertía ya sobre la Nueva Evangelización en el opulento mundo occidental que no encuentra un punto de contacto con las Iglesias institucionales y sus estructuras tradicionales refiriendo que:

En Alemania la Iglesia está organizada de manera óptima. Pero, detrás de las estructuras, ¿hay una fuerza espiritual correspondiente, la fuerza de la fe en el Dios vivo? Debemos decir sinceramente que hay un desfase entre las estructuras y el Espíritu. Y añado: La verdadera crisis de la Iglesia en el mundo occidental es una crisis de fe. Si no llegamos a una verdadera renovación en la fe, toda reforma estructural será ineficaz.

Esto se decía en el año 2011, desde el centro romano se propugna por una reforma de la Iglesia desde un punto de vista espiritual, hace una explicación teológica del problema, pero la misma gestión de la crisis le tocará de cerca al Cardenal Ratzinger y desde el pontificado como Benedicto XVI.

\section{Benedicto XVI ante la pederastia como crisis en la Iglesia}

La crisis de la pedofilia se venía gestando desde el pontificado de Juan Pablo II, bajo Benedicto XVI se afrontará la crisis como una urgencia y se denota cómo el centro romano reaccionará ante la incapacidad de las periferias eclesiales, de sus Episcopados ante el abuso sexual, Roma será artífice de una reforma y renovación espiritual y evangélica, gestionándola con concretas medidas penales canónicas a los abusadores.

Se cuestionó a Benedicto XVI (2008 a) sobre las causas del abuso de menores en su viaje a Estados Unidos, después de señalar la vergüenza de estos hechos indicaba los caminos a seguir: el camino de la justicia, los pederastas serían apartados del sacerdocio y ayuda a las víctimas; el de la pastoral, como curación, ayuda, asistencia y reconciliación con las víctimas y el cuidado en la formación espiritual de los candidatos al sacerdocio, insistiendo en su intensidad en la vivencia sacramental para estar unidos a Cristo.

En reunión con los Obispos norteamericanos, éstos señalaban diversos retos de la Iglesia americana en la evangelización, tales como el proceso silencioso de abandono de la fe, el relativismo en la vida intelectual, el alejamiento de la Misa y su identificación con la Iglesia, así como la disminución de las vocaciones, a lo que señalaba Benedicto XVI que la fe se ha transformado en aceptación pasiva de que ciertas cosas 'allí fuera' son 
verdaderas, pero sin relevancia práctica para la vida cotidiana. Se ha dado una separación creciente entre la fe y la vida: el vivir como si Dios no existiese.

De fondo ha existido, para Benedicto XVI (2008 b), un planteamiento individualista y ecléctico de la fe y la religión: alejándose de la perspectiva católica de 'pensar con la Iglesia', no ha habido, ante el catolicismo meramente social, una conversión integral e interior a la ley de Cristo, "más que transformarse y renovarse por dentro, los cristianos caen fácilmente en la tentación de acomodarse al espíritu mundano.”

En Estados Unidos se ha venido detectando una apostasía silenciosa reflejada en el abandono silencioso de la fe, no por rechazarse conscientemente esta fe en Cristo, pero que no han recibido fuerza vital de la liturgia, de los Sacramentos, de la predicación. La fe cristiana es esencialmente eclesial, sin un vínculo vivo con la comunidad, la fe del individuo nunca crecerá hasta la madurez.

El proceso de abandono de la fe se explica también por la pérdida de la noción de salvación en las sociedades modernas, el Evangelio mismo es una liberación de la realidad del mal y el don de una vida nueva y libre en Cristo, el mensaje de la Iglesia debe tender al despertar una sed de la plenitud que solamente Cristo puede dar.

La salvación se ofrece en la liturgia de la Iglesia, y sobre todo en el sacramento de la Eucaristía, es un cometido actual el rescatar el espíritu del Concilio y que los laicos en la liturgia también ejerzan su sacerdocio común que les servirá de impulso para un apostolado fructuoso en el mundo.

Se ha detectado también un eclipse casi total de un sentido escatológico en muchas de nuestras sociedades tradicionalmente cristianas, la fe y la esperanza son la inspiración y la base de nuestros esfuerzos para prepararnos a la llegada del Reino de Dios, se podría estar preparando una nueva primavera para la cristiandad, pero se requiere de la renovación del celo apostólico.

La renovación de la Iglesia en América y en el mundo depende de la renovación de la regla de la penitencia y del crecimiento en la santidad: inspirados y realizadas por el Sacramento de la Reconciliación.

Benedicto XVI (2010 a) señalaba algunas causas para entender el desconcertante problema del abuso sexual de niños de menores que obscurecieron la luz del Evangelio como no lo habían logrado ni siquiera siglos de persecución, entre otras se destacaban las siguientes en el caso de la Iglesia de Irlanda: 
- la transformación y secularización;

- el dejar de lado las prácticas sacramentales y devocionales que sostienen la fe y la hacen capaz de crecer;

- la tendencia, incluso por parte de sacerdotes y religiosos, a adoptar formas de pensamiento y de juicio de las realidades seculares sin suficiente referencia al Evangelio;

- el programa de renovación propuesto por el concilio Vaticano II a veces fue mal entendido;

- la tendencia, motivada por buenas intenciones, pero equivocada, a evitar los enfoques penales de las situaciones canónicamente irregulares;

- procedimientos inadecuados para determinar la idoneidad de los candidatos al sacerdocio y a la vida religiosa;

- insuficiente formación humana, moral, intelectual y espiritual en los seminarios y noviciados, $\mathrm{y}$, finalmente,

- el clericalismo, como una tendencia en la sociedad a favorecer al clero y otras figuras de autoridad y una preocupación fuera de lugar por el buen nombre de la Iglesia y por evitar escándalos, cuyo resultado fue la falta de aplicación de las penas canónicas en vigor y la falta de tutela de la dignidad de cada persona.

Benedicto XVI (2010 b) reflexionaba sobre estas causas del crimen de la pederastia, en un discurso apocalíptico interpretaba una visión mística de la alemana, Hildegarda de Bingen en el contexto gnóstico del catarismo medieval el cual propugnaba una reforma radical de la Iglesia por los abusos del clero:

Ella les reprochó duramente que quisieran subvertir la naturaleza misma de la Iglesia, recordándoles que una verdadera renovación de la comunidad eclesial no se obtiene con el cambio de las estructuras, sino con un sincero espíritu de penitencia y un camino activo de conversión.

Sin adentrarnos en el estudio del polémico texto de Benedicto XVI (2019) ${ }^{5}$ en el contexto del Encuentro 'La Protección de los menores en la Iglesia' que tuvo lugar en el Vaticano del 21 al 24 de febrero de ese año, fue un documento que levantó polémica pero sólo reforzó lo que ha venido argumentando desde teólogo, de Cardenal a Papa. 
Sólo destacaremos que en ese texto se pronuncia sobre el tema del empoderamiento intraeclesial, unas de las causas de la pederastia ha sido la idea de la conciliaridad, que refleja una tensión entre el centro romano y episcopados de otros países que sostendrían una actitud crítica o negativa hacia la tradición y que pretendieron reemplazarla por un nuevo espíritu (Zeitgeist), radicalmente abierto con el mundo y que influyó en el nombramiento y designación de los Obispos, que buscaron una 'nueva y moderna catolicidad' a lo cual afrontó Juan Pablo II en el nombramiento de nuevos Obispos o epíscopos.

Ciertamente que hay poderes burocráticos tanto en el centro como en la periferia, en el caso de la pederastia los Obispos norteamericanos, con el problema ya en marcha, resolvían los asuntos con ese dejo de conciliaridad y no se castigaba a los culpables de la pedofilia, por lo que se ha denominado el garantismo (proteccionismo procesal) de las leyes penales canónicas a las que se enfrentó Ratzinger ya desde Prefecto de la Sagrada Congregación para la Doctrina de la Fe.

No cabe duda que la crisis del abuso de menores en la Iglesia fue una crisis de disciplina (además de moral, espiritual), por eso, como sostiene Regoli (2018), "Si la inadecuación de los obispos ante la crisis de los abusos de menores obliga a Roma a intervenir, y después a centralizar, no por esto la misma Roma consigue llevar a cumplimiento todos los proyectos de renovación del cuerpo jerárquico de obispos" (p. 191), porque en el fondo se encuentran visiones de la Iglesia, y desde luego, de la Fe como hemos estando analizando.

\section{Sinodalidad y Reforma eclesial: la propuesta del Papa Francisco ante el clericalismo}

El pontificado de Francisco no ha sido ayuno de polémicas y tensiones surgidas por otros casos del abuso sexual de menores como el caso de Chile. Sólo para analizar la propuesta y las consideraciones que Francisco (2019 b) tiene sobre esta crisis eclesial tomaremos a consideración el referido Encuentro sobre la protección de la niñez, celebrado en el Vaticano.

La causa de la pederastia, tan compleja porque se ha dado en tantos contextos y es un fenómeno mundial, ha hecho reflexionar al Papa Francisco sobre el significado de este mal:

ante todo este sacrificio idolátrico de niños al dios del poder, del dinero, del orgullo, de la soberbia, no bastan meras explicaciones empíricas; 
estas no son capaces de hacernos comprender la amplitud y la profundidad del drama...la hermenéutica positivista demuestra su propio límite. Nos da una explicación verdadera que nos ayudará a tomar las medidas necesarias, pero no es capaz de darnos un significado...necesitamos tanto explicaciones como significados. Las explicaciones nos ayudarán mucho en el ámbito operativo, pero nos dejan a mitad de camino. ¿Cuál es, por tanto, el 'significado' existencial de este fenómeno criminal? Teniendo en cuenta su amplitud y profundidad humana, hoy no puede ser otro que la manifestación del espíritu del mal...Detrás y dentro de esto está el espíritu del mal que en su orgullo y en su soberbia se siente el señor del mundo [satanás] y piensa que ha vencido.

El remedio eclesial no es otro más que el de la santidad, la purificación y, para el caso de los sacerdotes, según Francisco (2019 b), la vivencia plena del celibato (Punto 4), retomando los principios que el Papa Pablo VI había sostenido en un documento polémico intra eclesial de 1967, la Encíclica Sacerdotalis caelibatus, en pleno posconcilio. Es decir, el problema no es el celibato sino vivirlo en medio de tantas transformaciones de mentalidades y estructuras, lo cual sigue vigente y propuesto por el centro romano ante las posturas en contra o por abolirlo que surgen en las periferias.

Celibato para los sacerdotes y santidad para ellos y para los laicos, sólo una Iglesia profética, en su silencio cotidiano, continúa haciendo visible y afirmando la esperanza que Dios no abandona, éste Pueblo será el que nos libre de la plaga del clericalismo, que es el terreno fértil para todas estas abominaciones.

Se puede ver claramente la visión espiritual y teológica que sostiene constantemente Francisco, en el contexto alemán señalaba a los Obispos sobre la erosión de la fe católica que se ha venido detectando desde tiempo atrás, advertía sobre la simplicidad de la evangelización en contraste con el aumentar la institucionalización, que no es más que un reflejo de este proceso de clericalización, de reducir el evangelio a meras estructuras en las que se participe, en el empoderamiento o en el riesgo de la institucionalización:

Se inauguran estructuras siempre nuevas, que finalmente carecen de fidelidad. Es una especie de pelagianismo que nos lleva a confiar en las estructuras administrativas, en organizaciones perfectas...La Iglesia 
está viva, se presenta a los hombres en su realidad, sabe cómo preocuparse y cómo animarse. No tiene una cara rígida, tiene un cuerpo que se mueve, crece y siente: es el cuerpo de Jesucristo (Francisco, 2015).

Lo que se necesita es la conversión pastoral, que las estructuras de la Iglesia se vuelvan más misioneras, que se ataque cierta mundanalidad que deforma las almas, sofoca la conciencia de la realidad y se vive en un mundo artificial que se construye, sin ver el exterior e insistía en que sin Sacerdote no hay Eucaristía.

Francisco (2019 c) en un significativo documento dirigido a la Iglesia alemana ha resaltado la doble perspectiva de la sinodalidad, una que va desde abajo hacia arriba, que exista el deber de cuidar la existencia y el buen funcionamiento de la Diócesis: los consejos, las parroquias y la participación de los laicos y después la sinodalidad desde arriba hacia abajo donde se viva de manera específica y singular la dimensión Colegial del ministerio episcopal y del ser eclesial.

Recuerda Francisco que la Iglesia como peregrina en la tierra lleva el tesoro, de la que es 'constitutivamente portadora' en vasijas de barro, por esto no es perfecta en este mundo $\mathrm{y}$ advierte sobre un sano aggiornamento, que estimule "generar y poner en marcha procesos que nos construyan como Pueblo de Dios más que la búsqueda de resultados inmediatos que generen consecuencias rápidas y mediáticas pero efímeras por falta de maduración o porque no responden a la vocación a la que estamos llamados" (2019 c, Punto 3).

El caminar juntos evitara que nos instalemos en recurrentes esquemas y mecanismos que acaben desnaturalizando o limitando la misión de la Iglesia, con el riesgo de caer en un juego de argumentaciones, disquisiciones y resoluciones que no hacen más que alejarnos del contacto real y cotidiano del pueblo fiel y del Señor.

A veces no se pueden solucionar los problemas desde reformas puramente estructurales, orgánicas o burocráticas que obedecen a la lógica pelagiana de que sólo el hombre es capaz de construir su propia salvación o al espíritu del paradigma tecnocrático que pretende “un buen cuerpo eclesial bien organizado y hasta 'modernizado' pero sin alma y novedad evangélica; viviríamos un cristianismo 'gaseoso' sin mordedura evangélica" (Francisco, 2019 c, Punto 5). 
Los problemas eclesiales deben ser vistos en clave teologal, dejar que la irrupción del Espíritu Santo sea la luz y guía para que la comunidad eclesial no pretenda resolver sola de sus problemas confiando y focalizándose exclusivamente en sus fuerzas o en sus métodos, su inteligencia, su voluntad o prestigio.

Es decir, que la Iglesia sea engendrada, no construida, en nosotros, la "transformación verdadera responde y reclama también exigencias que nacen de nuestro ser creyentes y de la propia dinámica evangelizadora de la Iglesia, reclama la conversión pastoral” (2019 c, Punto 6), de lo que se trata es de transparentar el Evangelio frente a un mero pragmatismo de la vida cotidiana de la Iglesia, es urgente la conversión pastoral para que la evangelización sea un criterio-guía de la praxis eclesial, la Iglesia necesita evangelizarse a sí misma.

La Evangelización no debe buscar el reposicionamiento eclesial, ni adaptarse al espíritu del tiempo (el Zeigeist del que habla Benedicto XVI) en el que se pierda la originalidad y profecía en la misión de la Iglesia, ni buscar hábitos o prácticas que daban sentido a otros contextos culturales, para Francisco (2019 c) la evangelización "es un camino discipular de respuesta y conversión en el amor a Aquel que nos amó primero; un camino que posibilite una fe vivida, experimentada, celebrada y testimoniada con alegría" (Punto 7), de lo que se trata es de buscar primero el Reino de Dios y lo demás se dará por añadidura.

Francisco recuerda precisamente el espíritu del Concilio Vaticano II, ante la tendencia a la fragmentación y polarización, es pertinente no olvidar que el Sensus Ecclesiae "nos libera de particularismos y tendencias ideológicas para hacernos gustar de esa certeza del Concilio Vaticano II, cuando afirmaba que la Unción del Santo pertenece a la totalidad de los fieles" (2019 c, Punto 9).

Francisco advierte contra la tentación del gnosticismo que busca decir algo siempre nuevo y distinto de lo que la Palabra de Dios nos regalaba; el ilustrado, el avanzado pretende "ir más allá del nosotros eclesial que preserva de los excesos que atentan a la comunidad" (Punto 9).

La tentación del gnosticismo genera grupos ilustrados como si pretendieran tener el sensus eclesiae, no permiten ver, saborear y agradecer esa santidad que se desparrama en el pueblo de Dios paciente, en la santidad de la vida ordinaria. 
La santidad es el camino de todos, la Iglesia necesita de la reforma que implica precisamente la santidad, este déficit de la santidad es al que hay que combatir, la santidad siempre ha sido el camino de la Iglesia ante las crisis en su historia y la ha preservado de toda reducción ideológica cientificista y manipuladora, gnóstica o pelagiana.

La sinodalidad debe estar enmarcada en esta lógica evangelizadora y de búsqueda de la santidad, tiene que

ir siempre acompañada de la gracia de la conversión para que nuestro accionar personal y comunitario pueda representar y asemejarse cada vez más al de la kénosis de Cristo...nos libra de falsos y estériles protagonismos, nos desinstala de la tentación de permanecer en posiciones protegidas y acomodadas y nos invita a ir a las periferias para encontrarnos y escuchar mejor al Señor (Francisco, 2019 c, Punto 12).

La autojustificación y autopreservación del cristiano nos puede llevar a espirales sin salida y nos impedirá que la medicina espiritual que se necesita es adorar al Señor, el ser cristiano es saberse pertenecer a la Iglesia de los bienaventuranzas, la Resurrección del Señor es la que hace que la Iglesia siga hacia adelante, la Iglesia no está muerta.

\section{La gestión de la crisis por Francisco}

Lo que se necesita es esa reforma eclesial evangélica tan necesaria para responder a la crisis del abuso de menores, Francisco (2019 a) en vísperas del Encuentro sobre la protección de los menores en la Iglesia sostenía que no todo se reduce a problemas organizativos, la credibilidad de la Iglesia en Estados Unidos a raíz de la pederastia

no se resuelve por decretos voluntaristas o estableciendo simplemente nuevas comisiones o mejorando los organigramas de trabajo como si fuésemos jefes de una agencia de recursos humanos. Tal visión termina reduciendo la misión del pastor y de la Iglesia a mera tarea administrativa/organizativa en la 'empresa de la evangelización' (Punto $1)$.

No basta una nueva organización sino una metanoia, una conversión, la dimensión programática de la Iglesia supone una dimensión paradigmática que muestre el espíritu y el sentido de lo que se hace, es decir, el espíritu de la evangelización. De lo contrario, todo lo que se haga será mera auto referencialidad, auto preservación y autodefensa, "Será 
quizás un cuerpo bien estructurado y organizado, pero sin fuerza evangélica, ya que no ayudará a ser una Iglesia más creíble y testimonial” (Francisco, 2019 a, Punto 1).

Para una nueva estación eclesial se necesitan pastores y maestros del discernimiento en el paso de Dios por la historia, no de simples administradores, pues las ideas se discuten y las situaciones vitales de las Iglesias se hacen bajo el discernimiento, no para obtener la tranquilidad fruto de un equilibrio humano o de una votación democrática que haga vencer a unos sobre otros, este discernimiento posibilita comprender y escuchar la realidad, los signos de los tiempos.

El año 2019 estuvo marcado por este reformismo eclesial a la alemana y del que Francisco se ha pronunciado en la Carta a la Iglesia de Alemania ya aludida, pero también tuvo el Sínodo para la Amazonia en el mes de octubre de ese año, el cual tuvo muchos reflectores mediáticos, sobre todo, en el asunto sobre la posibilidad del acceso al sacerdocio para hombres casados haciéndose eco sectores del reformismo eclesial, proponiendo sus visiones del espíritu del posconcilio.

Francisco se pronunció sobre el tema de la organización y empoderamiento del poder clerical en razón del Sínodo de la Amazonia en el que se refleja claramente su idea de promover una cultura más laical que contraste con la clerical, ampliando los horizontes más allá de los conflictos suscitados muchas veces por ofrecer soluciones pragmáticas diversas a los problemas enfrentados, como en el caso de la organización eclesial y la ministerialidad.

Por eso se trata de ir trascendiendo la dialéctica de estos enfrentamientos, así se resume lo que reflexiona Francisco (2020) en el capítulo sobre el sueño eclesial:

- sobre la inculturación de la ministerialidad, el modo como se estructuran y se viven los ministerios eclesiales es para el servicio de una mayor frecuencia de la celebración de la Eucaristía, aun en las comunidades más remotas y escondidas, se necesitan ministros que puedan comprender desde dentro la sensibilidad y las culturas amazónicas (Punto 86).

- El modo de configurar la vida y el ejercicio del ministerio de los sacerdotes no es monolítico, tiene diversos matices, es importante determinar qué es lo más específico del sacerdote, aquello que no puede ser delegado: la respuesta está en el sacramento del Orden sagrado, que lo configura con Cristo sacerdote. 
- Este carácter exclusivo recibido en el Orden, capacita sólo al sacerdote para presidir la Eucaristía, se trata de una función específica, principal e indelegable y Francisco cita como base un documento magisterial bajo el Pontificado de Juan Pablo II que ha definido la naturaleza y la cuestión teológica sobre el sacerdocio, la mujer no puede acceder al orden del sacerdocio ministerial y la Eucaristía no es un acto de la comunidad reunida, es Sacrificio de Jesucristo. ${ }^{6}$

Francisco sostiene cómo algunas corrientes ideológicas piensan que lo que distingue al sacerdote es el poder, el hecho de ser la máxima autoridad de la comunidad. Siguiendo a Juan Pablo II explica que aunque el sacerdocio se considere 'jerárquico', no significa que esté por encima del resto de los bautizados, sino que la función del sacerdote se encuentra ordenada totalmente a la santidad de todos los miembros del Cuerpo místico de Cristo, cuyo 'poder' es el de hacer correr la gracia para la Iglesia (Punto 87).

El sacerdote sólo es signo de Cristo Cabeza, esa es su gran 'potestad', que sólo puede ser recibida en el sacramento del Orden sacerdotal. El ministro ordenado únicamente puede decir: 'Esto es mi cuerpo', 'Yo te absuelvo de tus pecados', en la Eucaristía y en la Reconciliación, se implican un poder de gracia en el que el perdón sacramental está al servicio de una celebración eucarística digna (Punto 88).

- En el documento final de la Amazonia se trata de encontrar un modo de asegurar el ministerio sacerdotal, los laicos podrán anunciar la Palabra, enseñar, organizar sus comunidades, celebrar algunos sacramentos, buscar distintos cauces para la piedad popular y desarrollar la multitud de dones que el Espíritu derrama en ellos (Punto 89).

- La Eucaristía es el gran sacramento que significa y realiza la unidad de la Iglesia y anima a las comunidades a estar repletas de vida, por ello se necesitan sacerdotes, sin que se excluya que ordinariamente los diáconos permanentes, las religiosas y los mismos laicos asuman responsabilidades importantes para el crecimiento de las comunidades y que maduren en el ejercicio de esas funciones (Punto 91).

- No se trata sólo de facilitar una mayor presencia de ministros ordenados que puedan celebrar la Eucaristía, sino el compromiso por una nueva vida en las comunidades derivada del encuentro con la Palabra y la maduración en la santidad a través de variados servicios laicales en el que se dé espacio a sus diversos carismas (Punto 93). 
- Esto supone en la Iglesia una capacidad para dar lugar a la audacia del Espíritu, para confiar y concretamente para permitir el desarrollo de una cultura eclesial propia, marcadamente laical, lograr una presencia capilar que sólo es posible con un contundente protagonismo de los laicos (Punto 94).

- Se trata de alentar en la Iglesia una pastoral de conjunto con prioridades diferenciadas, distinguir los papeles de cada bautizado en la tarea evangelizadora.

- En la Amazonia hay comunidades que se han sostenido gracias a las mujeres: bautizadoras, catequistas, rezadoras, misioneras, ciertamente llamadas e impulsadas por el Espíritu Santo, Francisco destaca sobre el

evitar reducir nuestra comprensión de la Iglesia a estructuras funcionales. Ese reduccionismo nos llevaría a pensar que se otorgaría a las mujeres un status y una participación mayor en la Iglesia sólo si se les diera acceso al Orden sagrado. Pero esta mirada en realidad limitaría las perspectivas, nos orientaría a clericalizar a las mujeres, disminuiría el gran valor de lo que ellas ya han dado y provocaría sutilmente un empobrecimiento de su aporte indispensable (Francisco, 2020, Punto 100).

Nos encontramos pues ante un diálogo entre el Esposo y la esposa, la Iglesia, que se eleva en la adoración y santifica a la comunidad, lo cual, insiste Francisco "no debería encerrarnos en planteamientos parciales sobre el poder en la Iglesia," (Punto 101) porque Dios ha querido manifestar su poder y su amor a través de dos rostros humanos: el de su Hijo divino hecho hombre y el de una creatura que es mujer, María.

Se reconoce el papel trascendental de la mujer en la vida de la Iglesia bajo el modo de configurarse a la Virgen María que no fue sacerdotisa, con ello "no nos limitamos a un planteamiento funcional, sino que entramos en la estructura íntima de la Iglesia” (101), el poder característico de la mujer se muestra en ser fortaleza de esas comunidades de la Amazona y de toda la Iglesia.

Lo cual no quiere decir que las mujeres en la Iglesia sinodal puedan desempeñar otras funciones y servicios eclesiales que no requieren el Orden sagrado, del sacerdocio, ellas están llamadas a tener una incidencia real y efectiva en la organización, en las decisiones más importantes y en la guía de sus comunidades, con su propio estilo, su impronta femenina. 
Pudiera parecer, y lo es, un documento estrictamente eclesial, pero se ve claramente como Francisco se pronuncia contra el clericalismo que se busca, paradójicamente, por parte de sectores de laicos muy comprometidos en esas tareas de empoderamientos en los catolicismo periféricos como el alemán y que estaba latente en el Sínodo de la Amazonia por demás mediático en diversos medios de comunicación internacionales.

\section{CONCLUSIÓN}

La crisis de la Iglesia motivada por el abuso de menores en su seno ha hecho que se tome conciencia de una auténtica reforma pero han surgido diversas respuestas para ver de qué manera debe hacerse, así, por una parte se tiene un reformismo del catolicismo de la periferia que, en el espíritu del pensamiento del pos concilio ha buscado un cambio de estructuras, mejores instituciones, el caso paradigmático ha sido el camino sinodal que ha emprendido la Iglesia alemana pero que ha influido en otras latitudes eclesiales, como fue el caso de las reflexiones en torno al Sínodo de la Amazonia.

Por otra parte, los Papas Benedicto XVI y Francisco han insistido en un cambio fundamental que implicaría una renovación evangélica, teologal, más espiriritual; en el más franco contexto interpretativo del Vaticano II se han propuesto un programa reformista que toma como presupuesto la Evangelización misma, la Iglesia debe evangelizarse y no olvidar su misión profética.

Benedicto XVI ha partido de la crisis de la Fe, del sentido de Dios, ha reflexionado sobre el papel de la Iglesia universal y de las Iglesias particulares. Francisco ha puesto su programa reformista en la auténtica sinodalidad, el que la Iglesia se encuentra caminando en el mar proceloso del mundo y es llamada a ser una Iglesia en salida, al encuentro del hombre y ha advertido sobre las tentaciones del pelagianismo y del gnosticismo, para los que sólo cuenta las fuerzas del mismo hombre y del estar fuera del sentir de la Iglesia.

La Iglesia necesita de reforma es algo incuestionable, pero se tendrían por una parte un modelo de gestión que responde a la lógica del empoderamiento con el riesgo ya referido de una nueva clericalización como se ha propuesto por parte de teólogos y pastores con ideas posconciliares sobre nuevos modelos eclesiales. Por otro lado, una parte de la Iglesia institucional sugiere una auténtica reforma de la Iglesia que pasa por la santidad y conversión constante de sus miembros, de todos, de laicos, de pastores, habiéndose implementado modelos de gestionar la crisis, primero, con el establecimiento de penas canónicas a los infractores que viene del centro romano. Se trataba de la expulsión del 
estado clerical de los infractores de estos delitos y la renovación del espíritu del Vaticano II.

Crisis siempre ha tenido la Iglesia, las tentaciones son las mismas, o la reforma la hace el hombre a la manera pelagiana como insiste Francisco con su visión espiritual 'franciscana' o el hombre todo lo espera de Dios colaborando con el sí de la Fe, el dilema es reforma o empoderamiento clerical.

\section{REFERENCIAS BIBLIOGRAFICAS}

Arbeitspapier des vorbereitenden Forums. Macht und Gewaltenteilung in der Kirche (2019). Recuperado

de:

https://www.zdk.de/veroeffentlichungen/pressemeldungen/detail/-

Verantwortung-fuer-die-Sendung-der-Kirche--1269S/. Documento en PDF: file:///C:/Users/DCSA/Downloads/Arbeitspapier-des-Forums-Macht-und-

Gewaltenteilung\%20(3).pdf

Benedicto XVI. (2008 a). Conferencia de prensa durante el vuelo a Washington, Viaje Apostólico a los Estados Unidos y la Organización de las Naciones Unidas. Recuperado de: $\quad$ http://w2.vatican.va/content/benedictxvi/es/speeches/2008/april/documents/hf_ben-xvi_spe_20080415_intervista$\underline{\text { usa.html }}$

(2008 b). Encuentro con los Obispos de Estados Unidos. Respuestas de Su Santidad a las preguntas de los Obispos Americanos, Viaje Apostólico a los Estados Unidos y la Organización de las Naciones Unidas. Recuperado de: http://w2.vatican.va/content/benedictxvi/es/speeches/2008/april/documents/hf_ben-Xvi_spe_20080416_responsebishops.html

(2010 a). Carta pastoral a los católicos de Irlanda. Recuperado de: https://www.vatican.va/content/benedict-xvi/es/letters/2010/documents/hf_benxvi_let_20100319_church-ireland.html

(2010 b). Audiencia general. Recuperado de: http://w2.vatican.va/content/benedictxvi/es/audiences/2010/documents/hf_ben-xvi_aud_20100908.html

(2011). Discurso en el Encuentro con el Consejo del Comité Central de los Católicos alemanes (ZdK). Recuperado de: http://www.vatican.va/content/benedict- 
xvi/es/speeches/2011/september/documents/hf_ben-xvi_spe_20110924_zdkfreiburg.html

(2013). Discurso en el Encuentro con los párrocos y el Clero de Roma. Recuperado de: https://w2.vatican.va/content/benedict-

xvi/es/speeches/2013/february/documents/hf_ben-Xvi_spe_20130214_cleroroma.html

(2019). La Iglesia y los abusos sexuales. Recuperado de: https://www.aciprensa.com/noticias/el-diagnostico-de-benedicto-xvi-sobre-laiglesia-y-los-abusos-sexuales-35201

Congregación para la Doctrina de la Fe. (1983), Sacerdotium ministeriale, Carta a los Obispos de la Iglesia Católica sobre algunas cuestiones concernientes al Ministro de la Eucaristía. Recuperado de: https://www.vatican.va/roman_curia/congregations/cfaith/documents/rc_con_cf aith_doc_19830806_sacerdotium-ministeriale_sp.html

Francisco. (2018). Exhortación apostólica Gaudete et exsultate. Recuperado de: http://w2.vatican.va/content/francesco/es/apost_exhortations/documents/papafrancesco_esortazione-ap_20180319_gaudete-etexsultate.html\#El_gran_protocolo.

(2015). Discurso a los Obispos de la Conferencia Episcopal de la República Federal de Alemania en la visita ad limina. Recuperado de: http://w2.vatican.va/content/francesco/pt/speeches/2015/november/documents/p apa-francesco_20151120_adlimina-rep-fed-germania.html

(2019 a). Carta a los Obispos Estadounidenses que hacen los ejercicios espirituales en el seminario de Mundelein, Arquidiócesis de Chicago. Recuperado de: http://w2.vatican.va/content/francesco/es/letters/2019/documents/papafrancesco_20190101_lettera-vescovi-usa.html.

(2019 b). Discurso al final de la concelebración Eucarística del Encuentro 'La protección de Menores en la Iglesia.' Recuperado de: http://w2.vatican.va/content/francesco/es/speeches/2019/february/documents/pa pa-francesco_20190224_incontro-protezioneminori-chiusura.html 
(2019 c). Carta al Pueblo de Dios que peregrina en Alemania. Recuperado de: http://w2.vatican.va/content/francesco/es/letters/2019/documents/papafrancesco_20190629_lettera-fedeligermania.html

(2020). Exhortación Apostólica Postsinodal Querida Amazonia. Recuperado de: http://www.vatican.va/content/francesco/es/apost_exhortations/documents/papa -francesco_esortazione-ap_20200202_querida-amazonia.html

Marx, R. (2019). Transparency as a Community of Believers". Incontro 'La Protezione Dei Minori Nella Chiesa. Recuperado de: http://www.vatican.va/resources/resources_card-marxprotezioneminori_20190223_en.html

Ratzinger, J. (1992). La Iglesia. Una comunidad siempre en camino. Madrid, España. Ediciones Paulinas.

(2000). Conferencia del Cardenal Joseph Ratzinger sobre la Eclesiología de la 'Lumen Gentium' pronunciada en el Congreso Internacional sobre la aplicación del Concilio Vaticano II, Organizado por el Comité para el Gran Jubileo del año $2000 . \quad$ Recuperado de: http://www.vatican.va/roman_curia/congregations/cfaith/documents/rc_con_cfa ith_doc_20000227_ratzinger-lumen-gentium_sp.html (2005). Iglesia, Ecumenismo y Política. Madrid, España. BAC.

Pablo VI. (1967). Encíclica Sacerdotalis caelibatus, sobre el celibato sacerdotal. Recuperado de: $\quad$ https://www.vatican.va/content/paulvi/es/encyclicals/documents/hf_p-vi_enc_24061967_sacerdotalis.html

Regoli, R. (2018). El Pontificado de Benedicto XVI. Más allá de la crisis de la Iglesia. Madrid, España. Encuentro.

Vaticano II. (1964). Constitución Dogmática sobre la Iglesia Lumen Gentium. Recuperado de: https://www.vatican.va/archive/hist_councils/ii_vatican_council/documents/vatii_const_19641121_lumen-gentium_sp.html 